\title{
Theoretical Investigation of Oxazine 170 Perchlorate Doped Polymeric Optical Fiber Amplifier
}

\author{
Piotr Miluski, ${ }^{1}$ Marcin Kochanowicz, ${ }^{1}$ Jacek $\dot{Z}$ mojda, ${ }^{1}$ and Dominik Dorosz ${ }^{2}$ \\ ${ }^{1}$ Department of Power Engineering, Photonics and Lighting Technology, Bialystok University of Technology, Białystok, Poland \\ ${ }^{2}$ Department of Silicate Chemistry, AGH University of Science and Technology, Kraków, Poland \\ Correspondence should be addressed to Piotr Miluski; p.miluski@pb.edu.pl
}

Received 7 August 2017; Revised 25 October 2017; Accepted 6 November 2017; Published 23 November 2017

Academic Editor: Nunzio Salerno

Copyright (C) 2017 Piotr Miluski et al. This is an open access article distributed under the Creative Commons Attribution License, which permits unrestricted use, distribution, and reproduction in any medium, provided the original work is properly cited.

\begin{abstract}
Optical signal amplification in the waveguiding structure of optical fibers can be used for optical telecommunication systems and new light sources constructions. Organic dyes doped materials are interesting for new applications in polymeric optical fibers technology due to their benefits (efficient fluorescence, high absorption cross section, and easy processing). This article presents a numerical simulation of gain in poly(methyl methacrylate) optical fiber doped by Oxazine 170 Perchlorate. The calculated gain characteristic for the used dye molar concentration $\left(0.2 \cdot 10^{-6}-1.4 \cdot 10^{-6}\right)$ and pump power $(1-10 \mathrm{~kW})$ is presented. The fabricated fluorescent polymeric optical fiber is also shown. The presented analysis can be used for optical amplifier construction based on dye-doped polymeric optical fiber (POF).
\end{abstract}

\section{Introduction}

Organic electronics have become an alternative for inorganic based devices. The high quantum efficiency of organic fluorophores is useful in numerous optical applications: sensors, light sources, lasers, and amplifiers [1-10]. The high quantum yield of fluorescence was reported for laser organic dyes (xanthenes, oxazines, 7-aminocoumarins) [11]. Their structural properties allow incorporation directly into polymethyl methacrylate (PMMA) which is commonly used in polymer optical fiber technology. The spectroscopic properties of 7-(diethylamino)coumarin, Oxazine 170 Perchlorate, and codoped Perylene-Rhodamine 6G fibers were previously investigated [12-15]. Optical transmission can be easily obtained for PMMA attenuation optical windows of 465, 525,565 , and $650 \mathrm{~nm}$. The lowest attenuation of the PMMA core POF is approximately $100 \mathrm{~dB} / \mathrm{km}$ [16-18]. Much higher losses are observed for the infrared radiation spectrum. The high numerical aperture, the good optical transmission in the visible spectrum range, and the excellent mechanical and processing properties yield numerous constructions of optical fiber amplifiers and lasers based on PMMA matrix. Solventfree doping technique is especially desired in the polymeric fiber drawing technology. The impurities and solvent residues cause technological problems during the drawing process of polymeric fibers [16]. There are known luminescent organic and inorganic complexes in polymeric optical fiber technology. However, the absorption and emission cross sections of organic dyes are typically significantly higher than those observed in lanthanide ions, which are well known for their narrow absorption bands. Although the absorption cross section luminescence efficiency of lanthanides can be improved using organic ligands and energy transfer (antenna effect), the chelate molecules luminescence is quenched by PMMA nonradiative transitions and efficient luminescence can be observed only for triplet state europium $\left(\mathrm{Eu}^{3+}\right)$ and terbium $\left(\mathrm{Tb}^{3+}\right)$ complexes [19-26]. In such circumstances, organic dyes are frequently used in polymer optical fiber technology. The step and gradient refractive index profile and Rhodamine B, Rhodamine 6G, and Oxazine 4 optical amplifiers were presented [27-30]. The possibility of light amplification in organic dyes doped fibers is especially important in terms of compact devices fabrication as the absorption cross section is much higher than in rare earth ions. A recently developed semiconductor laser source in the visible range spectrum offers new applications in short VIS spectrum range for 


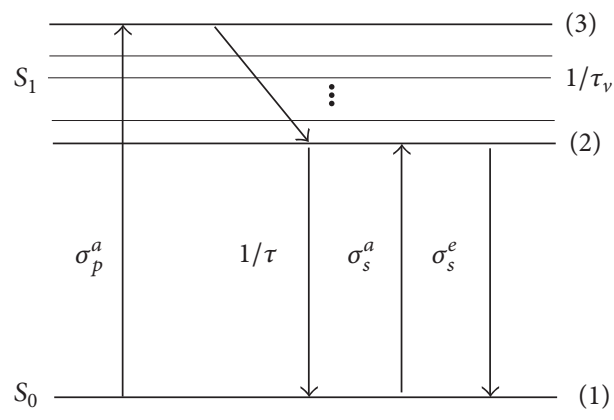

Figure 1: The simplified energy state scheme of the fluorophores.

optical signal amplification. The oxazines seem to be excellent candidates for this region due to the high absorption and emission cross section and direct PMMA doping possibility. Oxazine chromophore can be obtained by substitution of the xanthenes central carbon atom by nitrogen which, as a consequence, shifts the luminescence spectrum to a longer wavelength (ca. $80 \mathrm{~nm}$ ) [11]. The article presents a theoretical investigation of gain in polymeric optical fibers doped by Oxazine 170.

\section{Theoretical Background}

The fluorescence of organic dyes is widely used in laser technology of wavelength converters (typically in the solventdye mixture). New amplification possibilities appearing since fluorescent dyes were successfully used for polymeric optical fiber core doping (step or gradient refractive index profile). This idea can be easily applied to rigid polymer optical fibers. Some specific advantages (e.g., limited fluorescence self-quenching at low dye concentration) can be obtained using long affecting length in the waveguiding structure of the optical fiber. The coherent optical radiation (at a wavelength near the fluorescence maximum wavelength) can be amplified upon the excited state population which can be obtained by one-end or side excitation condition. Due to the fast depopulation of the excited state (lifetime typically few ns), amplification can be obtained only for the pulsed operating regime. The energy level scheme can be described as double wide energy bands as presented in Figure 1. The main excitation transition occurs from the ground (1) to a high energy excited state (3) but nonradiative transitions depopulate higher energy levels $((3) \rightarrow(2))$ and radiative emission occurs mostly from the lowest energy excited level (2).

$\tau_{v}$ (lifetime of level (3)) is significantly shorter than fluorescence lifetime $\tau$, and the three-level system can be simplified to a two-level system. Knowing the molar extinction coefficient $\varepsilon(\lambda)$, the absorption cross section can be calculated by

$$
\sigma^{a}(\lambda)=3.8 \cdot 10^{-21} \cdot \varepsilon(\lambda) .
$$

$\sigma_{s}^{a}$ and $\sigma_{s}^{e}$ are absorption and emission cross sections at the signal wavelength. The layout of the optical fiber amplifier system for the one-end excitation method is presented in Figure 2.
The relationship $\tau_{v} \ll \tau$ gives some simplification of the mathematical problem description. In such circumstances, the level (3) charge density is

$$
N_{3}(t, z) \cong 0
$$

The total charge densities expression is given by

$$
N_{T}=N_{1}(t, z)+N_{2}(t, z)
$$

where $N_{T}, N_{1}$, and $N_{2}$ are total, ground, and excited state charge densities, respectively.

The steady-state, time-dependent rate equations can be expressed as [27]

$$
\begin{aligned}
& \frac{\partial N_{2}(t, z, r)}{\partial t} \\
& \quad=\frac{2 \pi \cdot \sigma_{p}^{a} \cdot N_{1}(t, z) \cdot I_{p}(t, z)}{h v_{p}} \cdot \eta-\frac{N_{2}(t, z)}{\tau} \\
& \quad-\frac{2 \pi \cdot\left(\sigma_{s}^{e} \cdot N_{2}(t, z)-\sigma_{s}^{a} \cdot N_{1}(t, z)\right) \cdot I_{s}(t, z)}{h v_{s}} \\
& \frac{\partial I_{s}(t, z, r)}{\partial t} \\
& \quad=2 \pi \cdot\left(\sigma_{s}^{e} \cdot N_{2}(t, z)-\sigma_{s}^{a} \cdot N_{1}(t, z)\right) \cdot I_{s}(t, z) \cdot \eta \\
& \frac{\partial I_{p}(t, z)}{\partial t}=-2 \pi \cdot \sigma_{p}^{a} \cdot N_{1}(t, z) \cdot I_{p}(t, z) \cdot \eta,
\end{aligned}
$$

where $I_{p}(t, z)$ and $I_{s}(t, z)$ represent the pump and the signal power densities, $v_{p}$ and $v_{s}$ are frequencies for the pump and the signal wavelength, $h$ is Planck's constant (6.626 . $\left.10^{-34} \mathrm{~J} \cdot \mathrm{s}\right)$, and $z$ is the direction of radiation propagation. $\eta$ is the overlap integral of pump radiation distribution and dye concentration profile [27]:

$$
\eta=\int_{0}^{a_{0}} \Theta(r) \Psi(r) r d r
$$

where $\Theta(r)$ and $\Psi(r)$ are dye and excitation radiation distributions and $a_{0}$ is the dye profile radius. For the step profile of dye distribution, the function $\Theta(r)$ will be constant in the integral boundary, and in consequence $\eta$ will be a fixed value and is independent of the pump distribution. The dye and pump distributions used in the calculation are presented in Figure 3. 


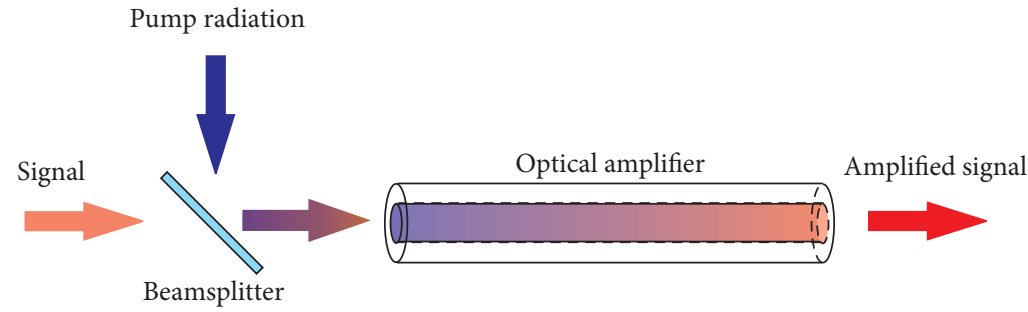

FIGURE 2: The layout of the optical fiber amplifier at one-end excitation.

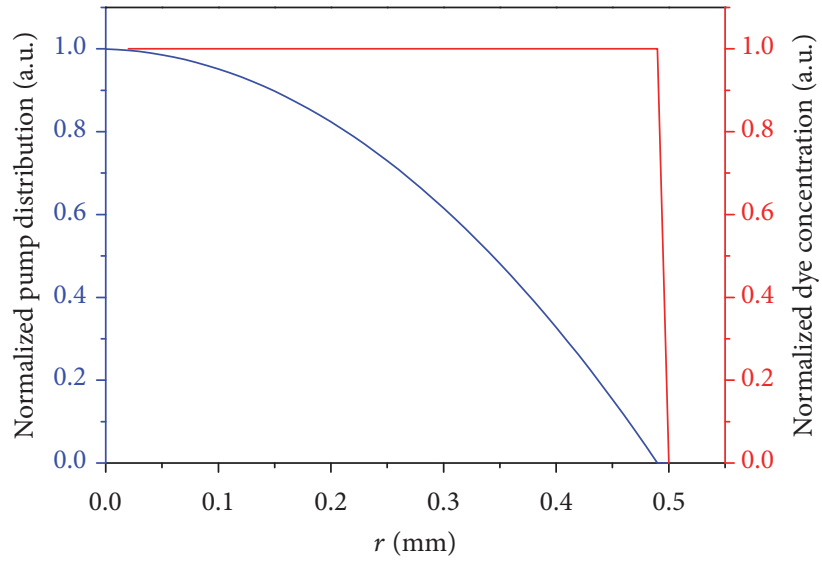

FIGURE 3: The normalized dye concentration and pump distribution.

In the steady-state conditions at a constant excited state population, the signal and pump intensities can be calculated using [27]

$$
\begin{aligned}
& \frac{\partial I_{s}(z, r)}{\partial z} \\
& =\eta \frac{\left(\left(\sigma_{s}^{e} \cdot \sigma_{p}^{a}\right) / h v_{p}\right) I_{p}(z)+\sigma_{s}^{a} / \tau}{\left(\sigma_{p}^{a} / h v_{p}\right) I_{p}(z)+\left(\left(\sigma_{s}^{e}+\sigma_{s}^{a}\right) / h v_{s}\right) I_{s}(z)+1 / \tau \eta} \\
& \quad \cdot I_{s}(z) N_{t}-k_{s} I_{s}(z), \\
& \frac{\partial I_{p}(z, r)}{\partial z} \\
& =-\eta \frac{\left(\left(\sigma_{s}^{e} \cdot \sigma_{p}^{a}\right) / h v_{s}\right) I_{s}(z)+\sigma_{p}^{a} / \tau}{\left(\sigma_{p}^{a} / h v_{p}\right) I_{p}(z)+\left(\left(\sigma_{s}^{e}+\sigma_{s}^{a}\right) / h v_{s}\right) I_{s}(z)+1 / \tau \eta} \\
& \quad \cdot I_{p}(z) N_{t}-k_{p} I_{p}(z),
\end{aligned}
$$

where $k_{p}$ and $k_{s}$ are attenuations estimated for pump and signal wavelength. The signal gain versus fiber length can be obtained using

$$
g(z)=10 \log \left(\frac{I_{s}(z)}{I_{s}(z=0)}\right)
$$

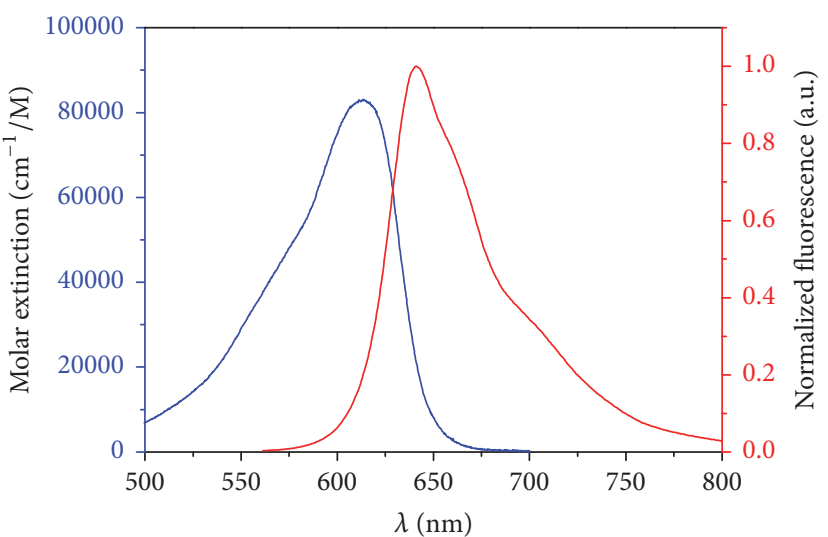

Figure 4: The absorption (blue)/emission (red) spectra of Oxazine 170 Perchlorate [31].

\section{Oxazine 170 Perchlorate Optical Fiber Amplifier}

Oxazine 170 was chosen to calculate the optical gain possibility in polymeric optical fiber structures. Poly(methyl methacrylate) was chosen as the host material. Using the Oxazine 170 dye, the maximum of emission $(645 \mathrm{~nm})$ corresponds to the most interesting transmission window for PMMA core fiber $(650 \mathrm{~nm})$ since low-cost laser diode sources and highly sensitive silicon-based photodiodes are commercially available for this spectrum range [32, 33].

The Oxazine 170 Perchlorate main absorption band is situated at $614 \mathrm{~nm}$ since the emission spectrum appeared at $641 \mathrm{~nm}$ as presented in Figure 4. The chosen parameters of the investigated dye-doped PMMA step-index amplifier are presented in Table 1.

The optical fiber amplifier parameters were calculated using steady-state time-independent equations ((6)-(7)). The simulations were carried out by varying the most important parameters in terms of signal amplification possibility using Runge-Kutta method and Matlab computational software. The simulation step $\left(d z=0.1 \cdot 10^{-3} \mathrm{~m}\right)$ was chosen to obtain convergent high accuracy results and short simulation time (less than $30 \mathrm{~s}$ on a quad-core CPU, $2.5 \mathrm{GHz}, 4 \mathrm{~GB}$ RAM).

High absorption and emission cross section (presented in Table 1) allow efficient amplification in the dye-doped optical fiber amplifier as it is presented in Figure 5. The pump radiation intensity (at wavelength $614 \mathrm{~nm}$ ) strongly decreases (according to the high absorption of this wavelength by 
TABLE 1: Parameters used for simulation of Ox170 doped optical fiber amplifier (estimated and from [34]).

\begin{tabular}{lcc}
\hline L.p. & Parameter & Oxazine 170 Perchlorate \\
\hline 1 & $\sigma_{p}^{a}:$ absorption cross section at the pump wavelength & $3.17^{-16} \mathrm{~cm}^{2}$ at $615 \mathrm{~nm}^{a}$ \\
2 & $\sigma_{s}^{a}:$ absorption cross section at the signal wavelength & $5.25^{-17} \mathrm{~cm}^{2}$ at $645 \mathrm{~nm}^{2}$ \\
3 & $\sigma_{s}^{e}:$ emission cross section at the signal wavelength & $4.20^{-16} \mathrm{~cm}^{2}$ at $645 \mathrm{~nm}$ \\
4 & $\tau:$ lifetime of level $(2)$ & $5.1 \mathrm{~ns}$ \\
5 & $\lambda_{p}:$ pump wavelength & $614 \mathrm{~nm}$ \\
6 & $\lambda_{s}:$ signal wavelength & $645 \mathrm{~nm}$ \\
7 & $n:$ refractive index & 1.493 \\
8 & $a_{0}:$ core radius & $0.5 \mathrm{~mm}$ \\
9 & $k_{p}:$ attenuation estimated for pump wavelength & $k_{p}=12 \mathrm{~dB} / \mathrm{m}$ \\
10 & $k_{s}:$ attenuation estimated for signal wavelength & $k_{s}=10 \mathrm{~dB} / \mathrm{m}$ \\
\hline
\end{tabular}

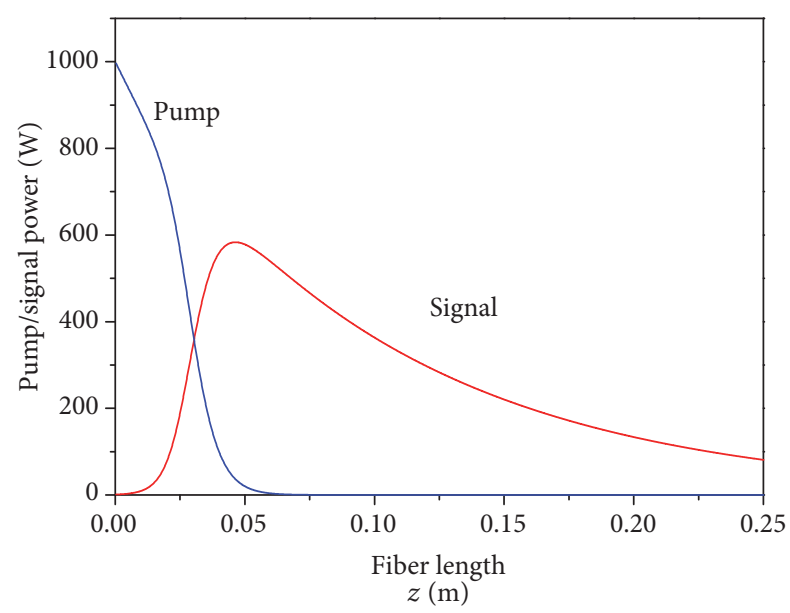

Figure 5: Pump (blue) and signal (red) intensity distribution versus fiber length in Oxazine 170 optical fiber amplifier; molar dye concentration: $2 \cdot 10^{-6}$; pump power: $1 \mathrm{~kW}$; signal power: $1 \mathrm{~W}$.

Oxazine 170). Excited electrons emit photons (transition from state $(2) \rightarrow(1)$ ) synchronously with signal photons (at signal wavelength $645 \mathrm{~nm}$ ). The optimum fiber length in terms of optical fiber amplifier construction is $0.046 \mathrm{~m}$ since the signal reaches its maximum.

The gain is strongly dependent on the dye concentration. Increasing the dye concentration results in high gain at a relatively low pump radiation power (Figure 6). Unfortunately, dye concentration has to be limited due to polymeric host doping possibility and fluorescence concentration quenching mechanism. Low concentration increases optimum optical fiber length $\left(0.28 \mathrm{~m}\right.$ for molar concentration $0.2 \cdot 10^{-6}$ versus 0.05 for molar concentration $\left.1.4 \cdot 10^{-6}\right)$. In fact, polymeric optical fiber amplifier lengths doped by highly fluorescent dyes are limited to few tenths of centimeters.

Assume that, at a low dye concentration, high gain can be obtained by increasing the pump intensity radiation as presented in Figure 7. For pump intensity from $1 \mathrm{~kW}$ to $10 \mathrm{~kW}$, the gain increases from $26.8 \mathrm{~dB}(z=0.059 \mathrm{~m})$ to $36.0 \mathrm{~dB}(z=$ $0.073 \mathrm{~m}$ ). The optimum amplification length changes are significantly smaller in comparison with those observed for dye

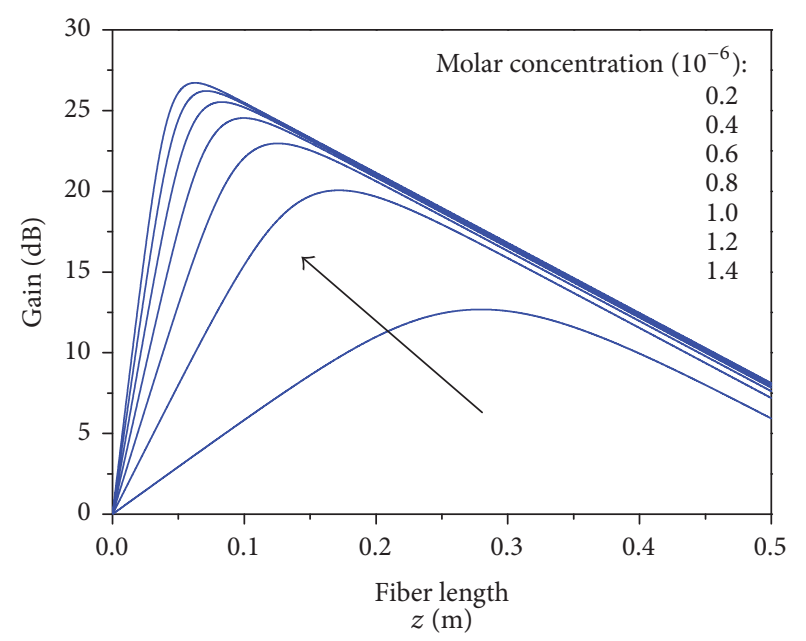

FIGURE 6: Gain calculated for the chosen dye concentration; pump power: $1 \mathrm{~kW}$, signal power: $1 \mathrm{~W}$.

concentration modifications (Figure 7). Moreover, both signals (pump and signal radiation) are attenuated in polymeric optical fiber structures. In such circumstances, the pump power radiation should be relatively high. Although the pulse pump power intensity of an order of $\mathrm{kW}$ was successfully used in polymer optical fiber amplifiers and stable gain parameters were obtained, the increase of photostability of fluorophores is one of the main issues considered in polymeric host based optoelectronic devices. Additionally, considering the application of Oxazine 170 doped PMMA fiber amplifier, it was experimentally verified that the fiber drawing process can be applied for fiber production (Figure 8). The fabrication process and measured luminescent properties were presented elsewhere [13].

\section{Conclusions}

The numerical simulation of gain in polymeric optical fibers doped by Oxazine 170 was presented. The step-index dye profile was used for calculations. The gain characteristic for the used dye molar concentration $\left(0.2 \cdot 10^{-6}-1.4 \cdot 10^{-6}\right)$ and pump power $(1-10 \mathrm{~kW})$ was presented. A maximum gain of 


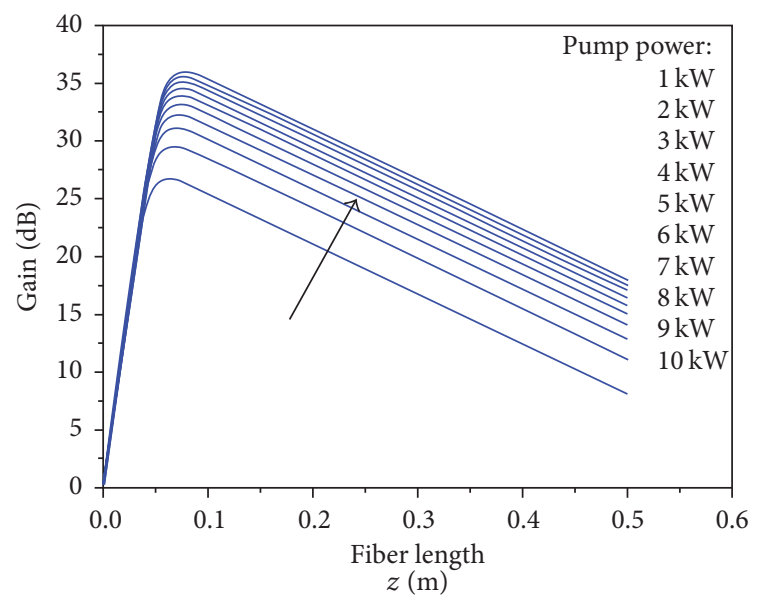

FIGURE 7: Gain calculated for the chosen pump power; molar dye concentration: $1.4 \cdot 10^{-6}$, signal power: $1 \mathrm{~W}$.

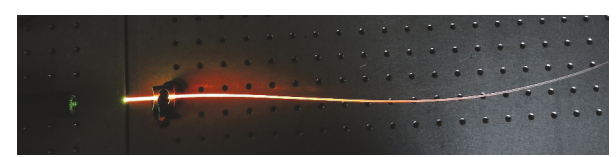

Figure 8: Fluorescence of Oxazine 170 Perchlorate doped PMMA fiber at one-end excitation $\left(\lambda_{\mathrm{exc}}=532 \mathrm{~nm}\right)$.

$36.0 \mathrm{~dB}$ was obtained for $10 \mathrm{~kW}$ and Oxazine 170 dye molar concentration $1.4 \cdot 10^{-6}$. The possibility of polymeric optical fiber fabrication was confirmed. The presented analysis can be used as a primary stage of optical amplifier construction based on Oxazine 170 Perchlorate.

\section{Conflicts of Interest}

The authors declare that there are no conflicts of interest regarding the publication of this article.

\section{Acknowledgments}

This work was supported by the National Science Centre (Poland) Project no. DEC-2017/01/X/ST8/00595 and under EU COST Action MP1401 "Advanced Fibre Laser and Coherent Source as Tools for Society, Manufacturing and Life Science."

\section{References}

[1] G. Williams, C. Backhouse, and H. Aziz, "Integration of organic light emitting diodes and organic photodetectors for lab-on-achip bio-detection systems," Electronics, vol. 3, no. 1, pp. 43-75, 2014.

[2] S. Z. Zardareh and F. A. Boroumand, "Degradation in organic light emitting diodes," World Academy of Science, Engineering and Technology, vol. 38, pp. 274-277, 2009.

[3] G. Zissis and P. Bertoldi, "2014 status report on organic light emitting diodes (OLED)," European Commission, Joint Research Centre, 2014.
[4] S. Sachdeva and A. Kumar, "Preparation and characterization of copolymer of benzene and perylene photoluminescence organic material," Research Journal of Applied Sciences, Engineering \& Technology, vol. 2, no. 6, pp. 589-591, 2010.

[5] Q. Xu, J. Ouyang, Y. Yang, T. Ito, and J. Kido, "Ultrahigh efficiency green polymer light-emitting diodes by nanoscale interface modification," Applied Physics Letters, vol. 83, no. 23, pp. 4695-4697, 2003.

[6] L. Bilro, N. Alberto, J. L. Pinto, and R. Nogueira, "Optical sensors based on plastic fibers," Sensors, vol. 12, no. 9, pp. 1218412207, 2012.

[7] P. Miluski, D. Dorosz, J. Zmojda, M. Kochanowicz, and J. Dorosz, "Luminescent polymer optical fibre sensor for temperature measurement," Acta Physica Polonica A, vol. 127, no. 3, pp. 730-733, 2015.

[8] P. Miluski, D. Dorosz, M. Kochanowicz, J. Zmojda, and J. Dorosz, "Luminescent optical fibre sensor for UV-A detection," in Proceedings of the Photonics Applications in Astronomy, Communications, Industry, and High-Energy Physics Experiments, Poland, June 2014.

[9] J. Zubia, "Plastic optical fibers: an introduction to their technological processes and applications," Optical Fiber Technology, vol. 7, no. 2, pp. 101-140, 2001.

[10] P. Miluski, D. Dorosz, M. Kochanowicz, J. Zmojda, and J. Dorosz, "The xanthene dyes doped PMMA microspheres for optical sensor applications," in Proceedings of the 16th Conference on Optical Fibers and Their Applications, Poland, September 2015.

[11] K. Drexhage, "Fluorescence efficiency of laser dyes," Journal of Research of the National Bureau of Standards Section A: Physics and Chemistry, vol. 80A, no. 3, p. 421, 1976.

[12] P. Miluski, M. Kochanowicz, J. Zmojda, and D. Dorosz, "Energy conversion in 7-(Diethylamino)coumarin doped PMMA fluorescent fibre," Optical and Quantum Electronics, vol. 49, no. 4, article 132, 2017.

[13] P. Miluski, "Luminescent Properties of Oxazine 170 Perchlorate Doped PMMA Fiber," Fibers, vol. 5, no. 2, 2017.

[14] P. Miluski, D. Dorosz, M. Kochanowicz, and J. Zmojda, "Fluorescent polymeric optical fibre illuminator," IEEE Electronics Letters, vol. 52, no. 18, pp. 1550-1552, 2016.

[15] P. Miluski, M. Kochanowicz, J. Żmojda, and D. Dorosz, "Emission properties and energy transfer in perylene-rhodamine $6 \mathrm{G}$ co-doped polymeric fiber," Chinese Optics Letters, vol. 14, no. 12, Article ID 121602, 2016.

[16] N. Ioannides, E. B. Chunga, A. Bachmatiuk et al., "Approaches to mitigate polymer-core loss in plastic optical fibers: A review," Materials Research Express, vol. 1, no. 3, Article ID 032002, 2014.

[17] U. H. P. Fischer, M. Haupt, and M. Joncic, Optical transmission systems using polymeric fibers, Optoelectronics - Devices and Applications, Padmanabhan Predeep, 2011.

[18] C. Lethien, C. Loyez, J.-P. Vilcot, N. Rolland, and P. A. Rolland, "Exploit the bandwidth capacities of the perfluorinated graded index polymer optical fiber for multi-services distribution," Polymer, vol. 3, no. 3, pp. 1006-1028, 2011.

[19] P. Miluski, M. Kochanowicz, J. Zmojda, and D. Dorosz, "Properties of Eu3+ doped poly(methyl methacrylate) optical fiber," Optical Engineering, vol. 56, no. 2, Article ID 027106, 2017.

[20] J. G. Bünzli and C. Piguet, "Taking advantage of luminescent lanthanide ions," Chemical Society Reviews, vol. 34, no. 12, pp. 1048-1077, 2005. 
[21] J. Kai, D. F. Parra, and H. F. Brito, "Polymer matrix sensitizing effect on photoluminescence properties of $\mathrm{Eu}^{3+}-\beta$-diketonate complex doped into poly- $\beta$-hydroxybutyrate (PHB) in film form," Journal of Materials Chemistry, vol. 18, no. 38, pp. 45494554, 2008.

[22] B. Chen, N. Dong, J. Xu et al., "Optical properties and spectroscopic parameters of Sm(TTA $)_{3}$ (TPPO $)_{2}$ doped PMMA," Optoelectron. Adv. Mater. Rapid Commun, vol. 1, pp. 609-613, 2007.

[23] H. Liang, Z. Yang, L. Xiao, and F. Xie, "Radiative transition probability of a europium (III) chelating polymer," Optoelectronics and Advanced Materials - Rapid Communications, vol. 4, no. 9, pp. 1396-1399, 2010.

[24] H. Jiu, J. Ding, Y. Sun, J. Bao, C. Gao, and Q. Zhang, "Fluorescence enhancement of europium complex co-doped with terbium complex in a poly(methyl methacrylate) matrix," Journal of Non-Crystalline Solids, vol. 352, no. 3, pp. 197-202, 2006.

[25] X. Chen and B. Yan, "In situ composition and photoluminescence of Tb, Eu centers/PMMA hybrid polymeric thick films," Journal of Optoelectronics and Advanced Materials, vol. 8, pp. 1931-1934, 2006.

[26] P. Miluski, M. Kochanowicz, J. Zmojda, and D. Dorosz, "Luminescent properties of $\mathrm{Tb}^{3+}$-doped poly(methyl methacrylate) fiber," Chinese Optics Letters, vol. 15, no. 7, Article ID 070602, 2017.

[27] J. Arrue, F. Jiménez, I. Ayesta, M. A. Illarramendi, and J. Zubia, "Polymer-optical-fiber lasers and amplifiers doped with organic dyes," Polymer, vol. 3, no. 3, pp. 1162-1180, 2011.

[28] M. Karimi, N. Granpayeh, and M. K. M. Farshi, "Analysis and design of a dye-doped polymer optical fiber amplifier," Applied Physics B: Lasers and Optics, vol. 78, no. 3-4, pp. 387-396, 2004.

[29] A. Tagaya, S. Teramoto, T. Yamamoto et al., "Theoretical and Experimental Investigation of Rhodamine B-Doped Polymer Optical Fiber Amplifiers," IEEE Journal of Quantum Electronics, vol. 31, no. 12, pp. 2215-2220, 1995.

[30] M. Sheeba, M. Rajesh, V. P. N. Nampoorj, and P. Radhakrishnan, "Fabrication and characterization of dye mixture doped polymer optical fiber as a broad wavelength optical amplifier," Applied Optics, vol. 47, pp. 884-889, 2008.

[31] H. Du, R.-C. A. Fuh, J. Li, L. A. Corkan, and J. S. Lindsey, "PhotochemCAD: A computer-aided design and research tool in photochemistry," Photochemistry and Photobiology, vol. 68, no. 2, pp. 141-142, 1998.

[32] A. Nespola, S. Abrate, R. Gaudino, C. Zerna, B. Offenbeck, and N. Weber, "High-speed communications over polymer optical fibers for in-building cabling and home networking," IEEE Photonics Journal, vol. 2, no. 3, pp. 347-358, 2010.

[33] I. T. Monroy, H. P. A. Vd Boom, A. M. J. Koonen et al., "Data transmission over polymer optical fibers," Optical Fiber Technology, vol. 9, no. 3, pp. 159-171, 2003.

[34] W. Blau, W. Dankesreiter, and A. Penzkofer, "Saturable absorption of dyes excited to the long-wavelength region of the S0S1 absorption band," Chemical Physics, vol. 85, no. 3, pp. 473-479, 1984. 


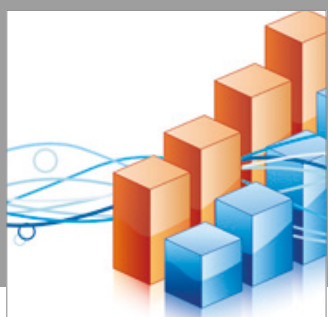

Advances in

Operations Research

vatersals

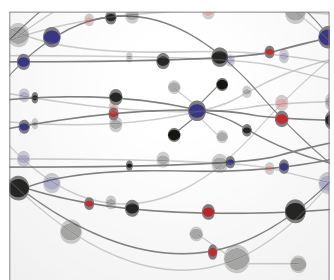

\section{The Scientific} World Journal
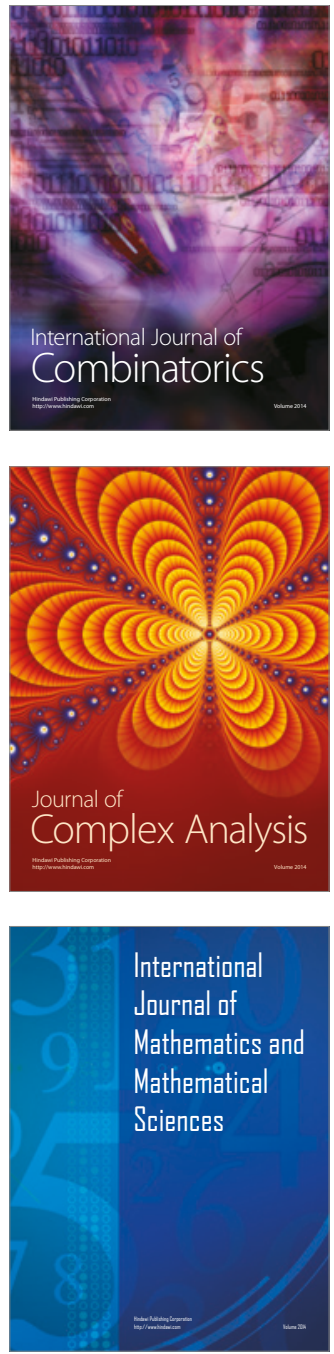
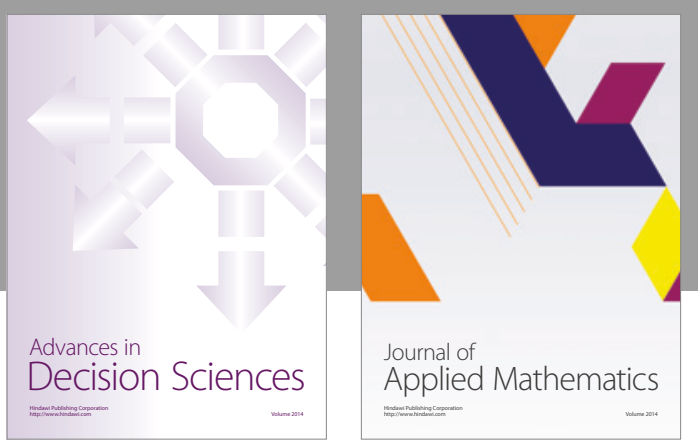

Algebra

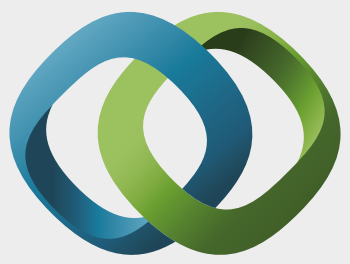

\section{Hindawi}

Submit your manuscripts at

https://www.hindawi.com
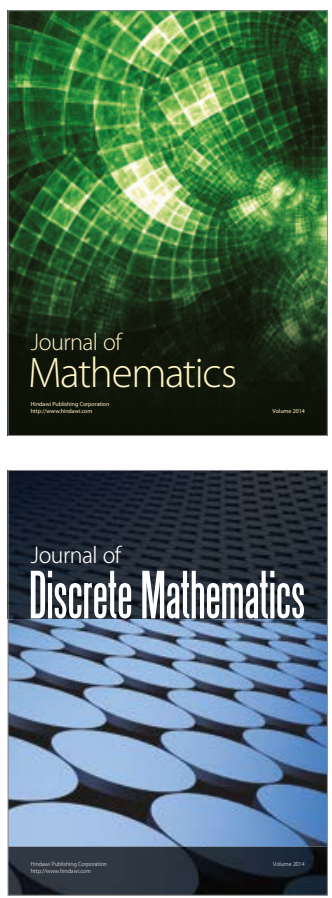

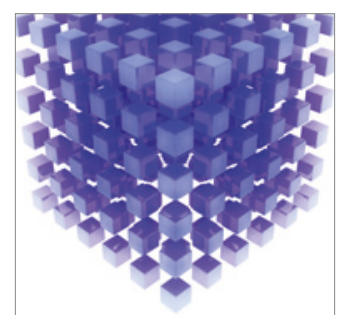

Mathematical Problems in Engineering
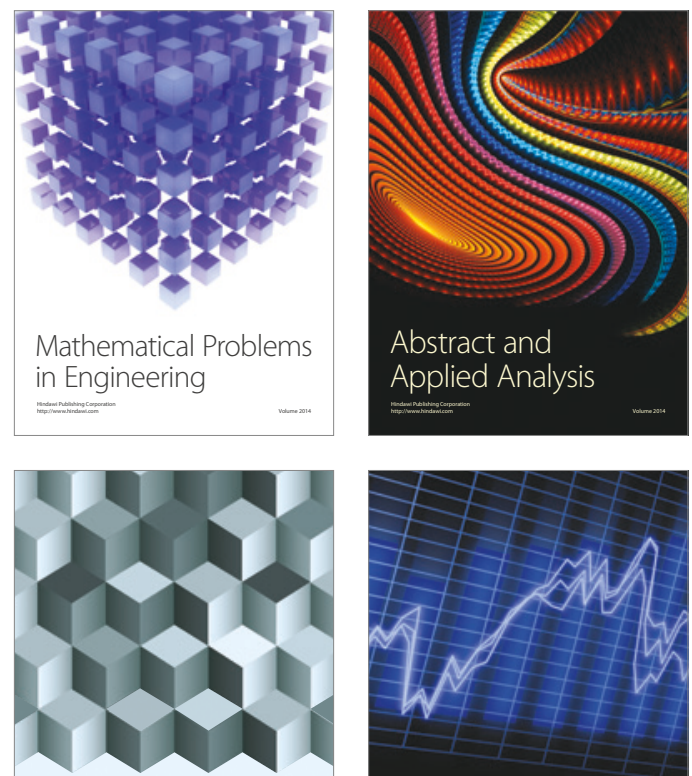

Journal of

Function Spaces

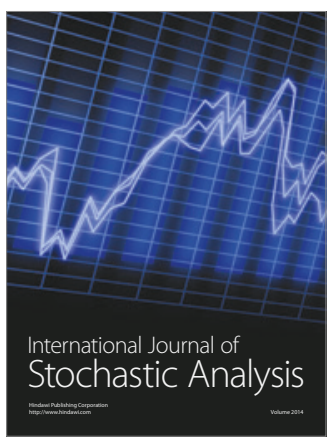

Probability and Statistics
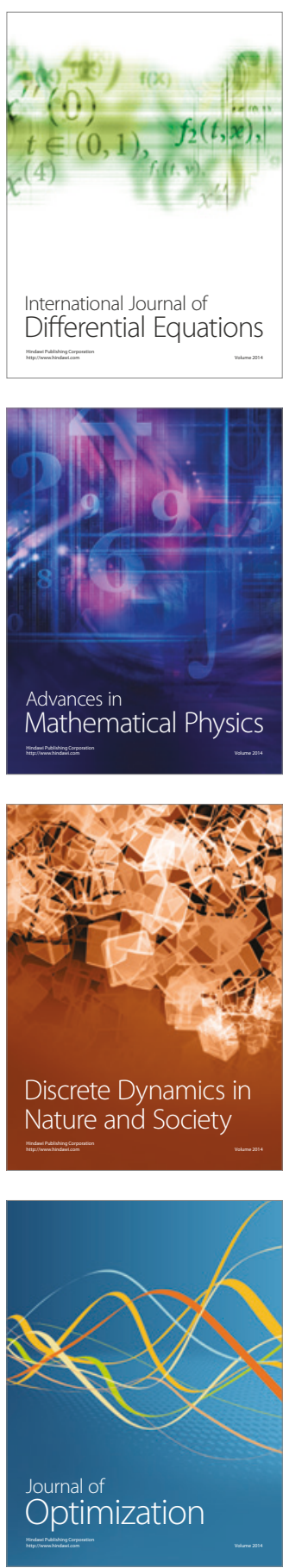